Article

\title{
Investigating the Influencing Factors of Teachers' Information and Communications Technology-Integrated Teaching Behaviors toward "Learner-Centered" Reform Using Structural Equation Modeling
}

\author{
Jing Zhang ${ }^{1}{ }^{\mathbb{D}}$, Zengzhao Chen ${ }^{1, *}$, Jingjing $\mathrm{Ma}^{2}$ and Zhi Liu ${ }^{3}$ \\ 1 National Engineering Research Center for E-Learning, Central China Normal University, \\ Wuhan 430079, China; jing@mails.ccnu.edu.cn \\ 2 School of Educational Information Technology, Central China Normal University, Wuhan 430079, China; \\ majingjing@mails.ccnu.edu.cn \\ 3 National Engineering Laboratory for Educational Big Data, Central China Normal University, \\ Wuhan 430079, China; zhiliu@mail.ccnu.edu.cn \\ * Correspondence: zzchen@mail.ccnu.edu.cn; Tel.: +86-133-0717-3855
}

Citation: Zhang, J.; Chen, Z.; Ma, J.; Liu, Z. Investigating the Influencing Factors of Teachers' Information and Communications

Technology-Integrated Teaching Behaviors toward "Learner-Centered" Reform Using Structural Equation Modeling. Sustainability 2021, 13, 12614. https://doi.org/10.3390/ su132212614

Academic Editors: Pilar Colás-Bravo and Jesús Conde-Jimenez

Received: 1 October 2021

Accepted: 11 November 2021

Published: 15 November 2021

Publisher's Note: MDPI stays neutral with regard to jurisdictional claims in published maps and institutional affiliations.

Copyright: (c) 2021 by the authors. Licensee MDPI, Basel, Switzerland. This article is an open access article distributed under the terms and conditions of the Creative Commons Attribution (CC BY) license (https:// creativecommons.org/licenses/by/ $4.0 /)$.

\begin{abstract}
In the context of information-driven Education transformation, this study investigates factors that influence the continuous transformation of teacher information and communications technology (ICT) teaching methods. Although some studies have found that teacher psychological cognition exerts different effects on different types of teacher ICT-integrated teaching behaviors, the current literature on influencing factors lacks the classification of behaviors. Based on the learnercentered transformation, this study divides teacher ICT-integrated teaching behaviors into teachercentered teaching behavior and student-centered teaching behavior, and constructs a hypothesis model of influencing factors on teacher ICT-integrated teaching behavior. We collected questionnaire data from 795 primary and secondary school teachers, then validated and adjusted the model through structural equation modeling (SEM). The social environment exerted a significant indirect impact on teacher technology application behaviors via mediation of teacher efficacy and outcome expectations. The two types of self-efficacy directly affected the student-centered ICT application behavior more than the teacher-centered ICT application behavior. The student-centered ICT application behavior exerted a significant impact on the teacher-centered ICT application behavior. This study confirms the significance of classifying teacher ICT-integrated teaching behavior and supports the transformation of learner-centered ICT-integrated teaching by improving the social environment to realize equitable and sustainable Education development.
\end{abstract}

Keywords: ICT-integrated teaching; digital teaching competence; teaching transformation; studentcentered teaching; structural equation method

\section{Introduction}

Information and communications technology (ICT) is a strategic tool for Educational development and reform in various countries, and the professional ability of teachers to teach information directly affects the quality of talent cultivation in the information age [1-3]. Thus, the influencing factors of ICT-integrated teaching behaviors have always been the focus of attention of researchers, and researchers have explored these factors from different angles. The diffusion of the innovation theory [4] proposed by Everett Rogers has been applied extensively to research on the influencing factors of teacher application of new technologies in teaching [5,6], as well as research on the development law of teaching reform and innovation [7]. In addition, the technology acceptance model (TAM) [8] is broadly used in the analysis of teacher willingness, attitude, and evaluation of using technology in teaching [9], and the technological pedagogical content knowledge (TPACK) 
is a common framework to investigate the influencing factors of the development stage of teachers of ICT-integrated teaching [10]. Moreover, research on the technical barrier of teacher application of ICT progresses gradually, from focusing on external factors such as facility matching, technical support, and organizational regulations, to focusing on internal psychological factors such as beliefs and attitudes to design thinking that correlates directly with practice [11-13]. However, these studies do not classify the t technology application behavior of teachers, which only explains how technology is adopted but does not reflect the differential impact of different ICT-teaching modes. Liu et al. [14] reported that individual psychological factors of teachers' "teacher-centered" technology application behaviors and "student-centered" technology application behaviors differ; the former correlates to the motivation of using technology for teaching while the latter does not, which implies the influencing factors of different technology behaviors differ.

On the classification of teachers' technology application behavior, we focused on the development direction of teaching reform. Student-centered teaching is considered a more conducive teaching method for nurturing student self-learning abilities and student development of deep learning and high-level thinking [15,16]; it helps harness student lifelong learning abilities and realizes sustainable development of student learning, which is considered a key shift for talent cultivation in the 21st century [17]. Meanwhile, the sustainable development of Education also needs to adapt rapidly to student-centered teaching reforms. Per UNESCO's Transforming Our World-2030 Agenda for Sustainable Development [18], training excellent teachers to adopt student-centered teaching methods is essential to attain equitable and quality Education and support lifelong learning. As early as 1998, China proposed "student-centered" curriculum reform in the Action Plan for the Revitalization of Education in the 21st Century [19]. Then, after stepping into the informatization 2.0 stage with integrated innovation as the development goal, the government advocated the use of new technologies to promote teacher Education [20] to help teachers improve digital teaching competence and developing into student-centered tutors. As a trend of China's Educational informatization development, the transition to learner-centered teaching leads the way in global teaching reform. The data collected in this study were based on the background of China's Educational informatization teaching reform; these results can be used as a reference for teaching transformations and the development of Educational informatization. Hence, this study divides teachers' technology application behavior into teacher-centered ICT application behaviors and student-centered ICT application behaviors, constructs a hypothesis model based on a literature review, and uses structural equation modeling to validate and explore differences in influencing factors between the two.

\section{Theoretical Basis}

To date, significant research has been conducted on teacher information technology application behaviors and beliefs, technology maturity, and organizational mechanisms [21-23]. This study highlights the sustainable development of information-based teaching ecology and focuses on constructing a more systematic hypothesis model. A comprehensive literature review was conducted guided by Bandura's social learning theory, which featured a high degree of abstraction and systematization. Hypotheses were proposed based on historical documents and followed by a comprehensively constructed hypothesis model.

In studying individual learning behaviors in real-life situations, American psychologist Bandura proposed a social learning theory, which states that both individual psychological factors and the environmental influence on human behavior [24] (pp. 59-64). In his view, all psychological changes are mediated by cognitive processes, regardless of the type of psychological changes; they influence an individual's behavioral decisions by changing their self-efficacy, which means an individual's belief in the implementation of some behavioral activities and the prediction of the ability to control them. Self-efficacy is classified as outcome expectation and efficacy expectation; the former is an individual's 
judgment of an event result, while the latter is an individual's judgment of their ability to handle the event [25] (pp. 33-36).

Hence, in the following sections, we will review environmental factors and individual factors, as shown in Figure 1. The classification of the environment adds the application environment to the social environment, which refers to research of technology acceptance [8], social environment (including interpersonal support and professional learning support for teachers), and the application environment (which refers to the configuration of hardware and software and how reasonable they are). In addition, an individual's sense of self-efficacy is classified as per Bandura [25]. The behavior classification was based on the classification of Liu et al. [20]. Our study proposes a hypotheses between the subdimensions based on historical literature and constructs a comprehensive hypothesis model.

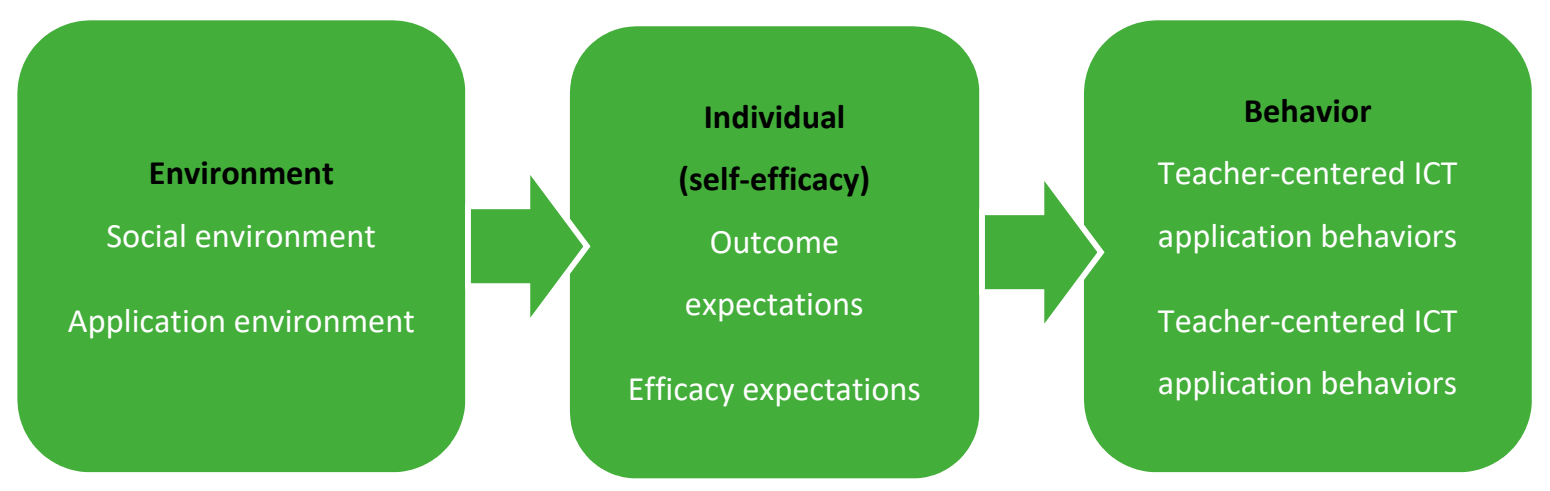

Figure 1. The research framework based on Bandura's social learning theory.

\section{Literature Review}

Scholars have examined the influencing factors of teacher ICT-integrated teaching behaviors based on the diffusion of innovation, TAM, technological obstacles, and TPACK [4-9]. All studies involved some factors that influenced teacher ICT-integrated teaching behaviors, and these factors are classified into two aspects, individual and environment, which align with Bandura's social learning theory. This study reviewed relevant research to investigate the factors that influenced different teacher ICT-integrated teaching behavior types, highlight the sustainability of Educational development, and propose hypotheses per the research framework based on Bandura's social learning theory.

\subsection{Personal Factors}

Individual self-efficacy directly regulates decision-making and behavior output [26] (pp. 45-46). Lai and Lin [27] mentioned that teachers with high self-efficacy tended to use ICT in more challenging ways. In the context of ICT-integrated teaching, the self-efficacy of teacher ICT application denotes their psychological assessment of ICT application in teaching, which included their belief in and attitude towards ICT-integrated teaching, and perception of their digital teaching competence. Self-efficacy of teachers using ICT-integrated teaching directly influences teacher adoption of and behavioral tendency towards technical practice. In general, research covered two specific types of self-efficacy, outcome expectation and efficacy expectation.

Outcome expectation comprises teacher belief in pleasure, anxiety, and positive and negative effects stemming from their teaching. Kim et al. [28] examined the concrete correlation between teacher outcome expectations and integration practice in a 4-year teacher development project funded by the United States Department of Education and reported that teacher outcome expectations in effective teaching methods directly correlated with integration of ICT-integrated teaching. Moreover, teachers with higher positive beliefs tend to adopt student-centered teaching methods and design more critical, creative, and cooperative tasks [29]. Also, outcome expectations not only correlated directly with 
behavior but also regulated behavior when hindered. Ertmer et al. [30] reported that teacher outcome expectations in ICT-integrated teaching are an intermediary factor, which adjusts the correlation between external obstacles to the application of technology perceived by teachers and their ICT application teaching behaviors. Nevertheless, simply improving teacher outcome expectations did not necessarily promote behavioral change, enhancing organizational management and systems were also indispensable.

Teacher efficacy expectations regarding ICT-integrated teaching focused primarily on the self-evaluation of their knowledge and skills when handling ICT-integrated teaching and often influenced their teaching behaviors. Joo et al. [22] used TAM to reveal that the self-efficacy of teacher ICT-integrated teaching affected their willingness to apply technology altogether. For teacher ICT-integrated teaching behaviors, it is not only the self-efficacy of ICT-integrated teaching but also the self-efficacy of the general technical abilities of teachers. Hatlevik and Hatlevik [31] illustrated that the self-efficacy of general technology is the basis for developing ICT-integrated teaching self-efficacy and teaching behaviors. Efficacy expectations not only directly influenced teacher behavior output but also played a role in adjustment when teachers faced obstacles in teaching practice, just like outcome expectation.

Although both outcome and efficacy expectations influence teacher ICT-integrated teaching behaviors, outcome expectation reflects more than the performance value of behavior, efficacy expectation often denotes the personal ability of teacher perception, and both affect ICT-integrated teaching behaviors. However, in previous studies, Mills et al. [32] reported on the immersive virtual environment (IVES) teaching of teacher ICTintegrated teaching beliefs, which means outcome expectations regarding ICT-integrated teachings have not been successfully transformed into practical behaviors. Therefore, they proposed that teacher professional development should focus on teacher reflective practical behaviors. Compared with IVES teaching beliefs, reflective practice promotes the improvement of teacher ability so that teachers have higher effectiveness expectations; this may suggest that teacher outcome expectations do not promote new challenging teaching behaviors and only efficacy expectation enhancements contribute to increasing teacher IVES teaching practice. Meanwhile, Ok et al. [33] reported on ICT-integrated teaching of special Education teachers that the perception of their own teaching methods and teaching content knowledge helped teachers cope with perceived difficulties and obstacles in iPad teaching. Both IVES and iPad teachings tended to be more student-centered. Thus, we suspect the efficacy expectation in self-efficacy affects both student-centered and teacher-centered ICT application behaviors, while the outcome expectation only affects teacher-centered behaviors. Hence, the following hypotheses are proposed:

Hypothesis 1 (H1). Efficacy expectation positively correlates with student-centered ICT application behavior.

Hypothesis 2 (H2). Efficacy expectation positively correlates with teacher-centered ICT application behavior.

Hypothesis 3 (H3): Outcome expectation positively correlates with teacher-centered ICT application behavior.

\subsection{Environmental Factors}

Regarding social environment influences, Mitchell et al. [34] demonstrated that a system environment facilitated the transformation and improvement of teacher informationbased teaching behaviors in a GIS software-based Technological Pedagogical Content Knowledge (TPACK) development project of geography teachers under the guidance of teacher and student exploratory learning theory. Optimizing structural factors comprised the learning community environment, expert feedback and guidance, and learning arrangements that facilitated continuous change for teachers. Khlaif and Kouraichi [35] examined the environment of teachers in Pakistani conflict areas and reported that violent conflicts, 
culture and religion, experience and belief, and other social factors affected the development of teachers in TPACK in this area. Meanwhile, Hatlevik and Hatlevik [31] reported that cooperation among teachers and the school administration exerted no significant impact on teacher ICT-integrated teaching behaviors; they attributed this to the notion that different groups of teachers have different needs for cooperation among colleagues and school systems, or differences in qualifications and teachers from different countries. In China's sociocultural environment, which leans towards collectivist, combined with teacher investigations and interviews, teachers sought guidance from experts and to communicate with colleagues during ICT-teaching exploration. A typical response was, "With the guidance of an expert, we can be determined from the confusion of turning to information-based teaching and know where to go." Thus, we believe the social environment affects not only teacher outcome expectations but also their efficacy expectations. Hence, we propose the following hypotheses:

Hypothesis 4 (H4). Social environment positively correlates with outcome expectation.

Hypothesis $\mathbf{5}$ (H5). Social environment positively correlates with efficacy expectation.

At the micro-level, many studies on promoting effective teaching demonstrated that school organization, resources, and teaching infrastructure significantly influenced teacher preparation, communication, and exploration [36]. Ertmer et al. [37] explored teacher ICT-integrated teaching behaviors and classified environmental support factors such as technical equipment, support, and training as primary barriers to teacher ICT-integrated teaching behaviors, while teacher knowledge, ability, and other internal factors were secondary barriers. Accordingly, Hew and Brush [38] and Kopcha [39] integrated resource and institutional barriers into first-level barriers. The obstacles of resources and systems directly affected teacher integrated teaching behaviors. Meanwhile, some studies further established that solving technology and resource allocations did not augment the quality of teacher technology application; however, the improvement of school mechanisms and teacher beliefs and attitudes promoted teacher information-based teaching behaviors [30,40]. Thus, we believe factors such as infrastructure and configuration affect teacher ICT-integrated teaching behaviors by influencing teacher outcome and efficacy expectations.

Besides the organizational environment at the micro-level, software is also an essential environmental factor for teacher ICT-integrated teaching; this is usually observed in research of technology maturity models and integrated TAM of the ICT-integrated teaching platforms. The ease of use and practicality of teaching software affected teacher willingness to use it, which affected application of ICT in teaching [41,42]. However, Walker et al. [43] used the TAM to conduct related research on the mobile teaching of Chinese interns and reported that despite the fact that ease of use and software practicality perceived by teachers strongly correlated, teacher willingness towards mobile teaching behaviors did not significantly correlate with software practicality and ease of use. Of note, these studies did not discuss whether the perception of teaching quality correlated with the teacher expectation of results or teacher perception of self-competence. Hence, we propose the following hypotheses:

Hypothesis 6 (H6). Application environment positively correlates with efficacy expectation.

Hypothesis 7 (H7). Application environment positively correlates with outcome expectation.

Furthermore, as student-centered teaching is a more complex form than teachercentered teaching, we propose the following hypothesis:

Hypothesis 8 (H8). Teacher-centered ICT application behavior positively correlates with studentcentered ICT application behavior. 


\subsection{Hypothesis Model}

Based on Bandura's social learning theory and related research, as well as the assumptions above, we proposed a hypothesis model (Figure 2).

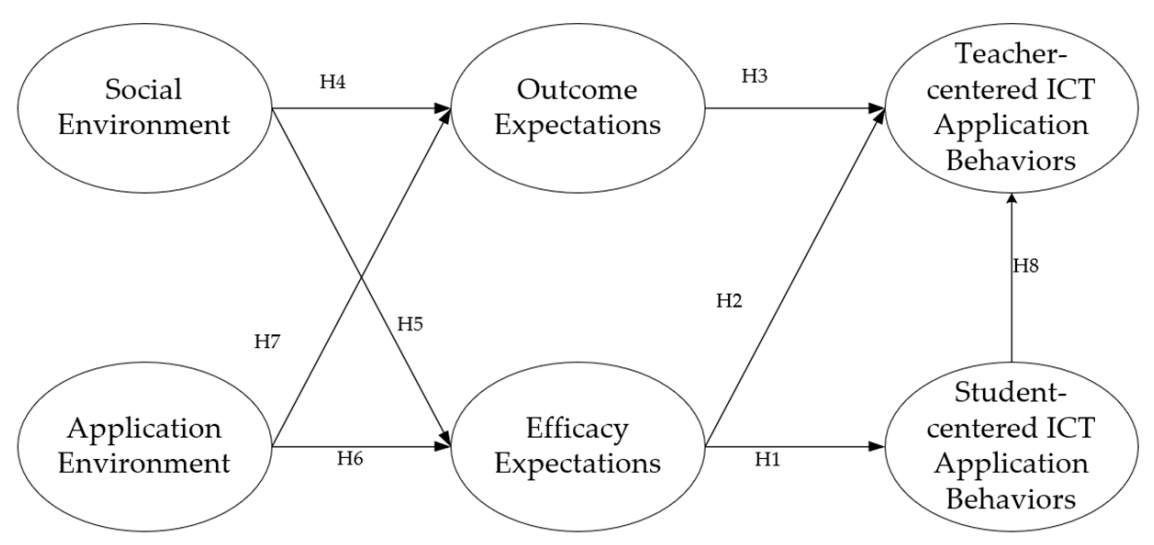

Figure 2. Hypothesis model of factors influencing student-centered and teacher-centered ICTintegrated teaching behaviors.

\section{Methodology}

\subsection{Procedure}

Based on the literature review and related theoretical guidance, we initially constructed a hypothetical model of factors influencing the two categories of teacher ICTintegrated teaching behaviors. In addition, a five-point questionnaire (in the Supplementary Materials) comprising 26 questions was formulated. The analysis process was divided into four steps. In the first step, to ensure questionnaire availability, we tested the questionnaire reliability using the reliability coefficient method and confirmatory factor analysis using SPSS18 [44]. In the second step, normed chi-square ( $\left.\chi^{2} / \mathrm{df}\right)$, root mean square error of approximation (RMSEA), standard root mean square residual (SRMR), comparative fit index (CFI), and Tucker-Lewis Index (TLI) tested model fitness by AMOS24 [45]. In the third step, model fitness was judged based on the model fit index. If the fit was not ideal, we followed the modified index result in AMOS, then added, deleted, or adjusted the model based on the theoretical and actual conditions until the model displayed goodness of fit [45]. In the fourth step, the standardized path coefficient was calculated using effect analysis to test the impact of different variables on target-dependent variables [46]. The effect analysis included direct and indirect effects. Direct effect denotes a direct influence between independent and dependent variables, whereas an indirect effect shows that the independent variable could influence the dependent variable through intermediaries such as outcome or efficacy expectations. Finally, we discuss the complex correlation between teacher behavior, environment, and psychological factors in the teaching system under the background of information technology.

\subsection{Participants and Data Collection}

In this study, the research was conducted quantitatively, and data collected from teacher questionnaire surveys. The participants were enrolled from 12 primary and secondary school teachers in three regions with different levels of economic development in China. School selection was conducted by regional administrators based on given requirements. To guarantee sample differences, four schools with different levels of informatization construction and application were selected for distribution. Despite different construction levels of these schools, informatization teaching equipment and functions were popular within the teaching environment. All teachers invited to complete the questionnaire had information teaching experience. The questionnaire was given online and distributed to 1004 teachers by the school administrator online work group to inform and encourage teachers to complete. A total of 795 questionnaires (response rate $79.2 \%$ ) were 
collected during March and April 2021. We eliminated data that took $<100 \mathrm{~s}$ to answer because an estimate determined it would take at least $100 \mathrm{~s}$ to complete the questionnaire carefully. Meanwhile, to ensure data quality, data with a repetition rate $>90 \%$ were excluded. This led to the exclusion of 281 questionnaires and the remaining 514 valid questionnaires were retained.

\subsection{Data Analysis}

To examine the eight research hypotheses, structural equation modeling (SEM) analyzed the data. SEM establishes, estimates, and tests causality relations. The model contained not only observable obvious variables but also non-directly observed latent variables. SEM can replace multiple regression analysis, path analysis, factor analysis, covariance analysis, and can clearly examine correlations among these latent variables [47]. In this study, SPSS18 and AMOS24 were used for data analysis. Regarding the sample size, different scholars have expressed different opinions. Quintana and Maxwell [48] proposed a sample size of at least 200 for more meaningful statistical results. The generally accepted standard is a sample size ten times larger than the number of observed variables [47]. This study contained six latent variables, reflected by 26 observation variables, and an effective sample size of 514, which fulfilled SEM data requirements.

\subsection{Survey Instruments}

Based on the Hatlevik and Hatlevik [31] "Teachers' ICT-integrated Teaching Behaviors Scale" and the standard functions of ICT-integrated teaching in China, we formulated nine questions (TC1-TC4, SC1-SC5) to describe teacher-centered ICT application behavior. Questions "I mainly used technology to support my interpretation when teaching" and "I would like to use technology to present a more precise subject knowledge structure" were used to describe how teachers use technology to support their explanations and better content display. Questions that describe the student-centered ICT application behavior included "I would like to use the network, video, software, etc., to support student cooperative learning and discussion" and "I would like to use media materials, online information, subject tools, etc., to guide students to explore solutions to real problems"; these questions described how teachers use technology to support student learning activities. This study was based on Holland and Piper [49], from the aspects of internal and external motivations to formulate outcome expectations of four questions (OE1-OE4). These questions describe the impact of using ICT in teaching on job performance, professional recognition, student learning effect, and career interest and include, "I think the use of technology in teaching can help students improve their learning effects" and "I think the use of technical teaching can improve my professional recognition in the organization." Sang et al. [50] examined the TPACK survey questionnaire, in which four questions regarding efficacy expectation were developed (EE1-EE4) and included teacher evaluation of their ability to discover technology problems in teaching and properly integrate technology problems into teaching, for example, "I can flexibly choose different teaching methods and techniques for different content" and "I can assist other teachers to integrate information technology, teaching methods, and teaching subjects." Based on Kopcha's [39] research on technical barriers, five social environment issues (SE1-SE5) in terms of infrastructure and professional support were formulated, including colleagues, leaders, experts, policy support, and professional learning opportunities that teachers need for ICT-integrated teaching. Those included, "I can get guidance from experts on the application of technology for teaching" and "I can get support and encouragement from the leader." Based on the user experience of teaching software satisfaction, four questions on the application environment were developed (AE1-AE4); they included the configuration of school equipment and resources, and the availability of software. These questions included "The resources in the digital teaching platform are useful" and "The function design of the teaching software is reasonable." Thus, a five-point Likert scale questionnaire of 26 questions was formulated, with 5 being the highest and indicating the occurrence of the most frequent event, receiving sufficient 
support, or completely agreeing, and 1 being the lowest, indicating an infrequent event occurrence, with almost no satisfaction, and completely disagreeing. These 26 questions were used as observed variables to reflect six dimensions, including student-centered ICT application behavior, teacher-centered ICT application behavior, outcome expectation, efficacy expectation, social environment, and application environment; all six are latent variables that cannot be observed directly.

\section{Results}

We conducted tests of the measurement and structural models [44]. Reliability, convergent validity, and discriminant validity were the common indicators to evaluate the measurement model, and the structural model was usually measured by the strength and direction among constructs.

\subsection{Assessment of Measurement Model}

Reliability primarily reflected the internal stability and consistent level of the measurement questionnaire, and the most commonly used indicator is Cronbach $\alpha$. Of note, Cronbach $\alpha>0.7$ indicates high questionnaire reliability. The overall Cronbach $\alpha$ for this questionnaire was 0.941 , and Cronbach $\alpha$ for each construct was $0.840-0.911$, suggesting high internal consistency between the latent variables, and high overall questionnaire reliability. Tavakol and Dennick [51] proposed that $\alpha>0.90$ may suggest redundancies. Thus, we carefully checked all items and determined a lack of redundant phenomena. Hence, the Cronbach value in this study was acceptable. In addition, convergence validity was measured by factor loading, composite reliability (CR), and average extraction variation (AVE). The factor loading for each item was $>0.50$, the CR for each construct was $>0.60$, and the AVE was $>0.50$ [51,52]; this demonstrated good model convergent validity. As shown in Table 1, CRs of six constructs were $>0.80$ and the AVEs of the six constructs were $>0.50$, which confirmed good convergent validity of this model.

Discriminant validity assesses the extent that one construct differs from another. Fornell and Larcker [52] suggested that the square root of the construct must exceed the correlations between items in any two constructs. As shown in Table 2, our model satisfies their criteria for discriminant validity. Having established the reliability, convergent validity, and discriminant validity of the constructs, the measurement model was adequate for this study; the observed variables in the measurement model of this study reflect the latent variables well. Furthermore, we further explored the correlation between the latent variables by using the structural model.

\subsection{Assessment of the Structural Model}

We focused on the following key goodness-of-fit values to test the overall fit of the structural model: (i) three absolute fit indices: normed chi-square $\left(\chi^{2} / \mathrm{df}\right)$, RMSEA, and SRMR, and (ii) two incremental fit indices: CFI and the TLI [44]. Although the normed chi-square is a critical indicator to measure the model's fit, its value is sensitive to the sample size and the complexity of the model [49]. As the sample size of this study was large $(n=514)$, the chi-square value $\left[\chi^{2}=847.00(p=0.000)\right]$ is not listed as the model evaluation standard. Many indicators to measure the model goodness-of-fit exist, including the absolute fit indices (e.g., $\chi^{2} /$ df, RMSEA, and SRMR) and incremental fit indices (e.g., CFI and TLI). Hu and Bentler [51] proposed acceptable fit thresholds of the structural model, which are $\chi^{2} / \mathrm{df}<3$, CFI $>0.90$, TLI $>0.90$, and RMSEA $<0.08$. Values obtained by AMOS24 were: $\chi^{2} / \mathrm{df}=2.97, \mathrm{CFI}=0.936$, TLI $=0.928$, and RMSEA $=0.062$. Those results confirmed that all indicators reached acceptable levels. However, the SRMR value was marginally larger than the critical SRMR standard of $0.08(0.081)$, and indicated an insufficient fit of the model data, which required adjusting the model. 
Table 1. Construct convergent validity $(n=514)$.

\begin{tabular}{|c|c|c|c|c|c|c|c|}
\hline & & Mean & SD & $\begin{array}{l}\text { Standardized } \\
\text { Loading }\end{array}$ & CR & AVE & Cronbach $\alpha$ \\
\hline \multirow{5}{*}{ Social Environment } & SE1 & 3.80 & 0.702 & 0.74 & \multirow{5}{*}{0.883} & \multirow{5}{*}{0.601} & \multirow{5}{*}{0.882} \\
\hline & SE2 & 3.47 & 0.805 & 0.84 & & & \\
\hline & SE3 & 3.63 & 0.754 & 0.81 & & & \\
\hline & SE4 & 3.64 & 0.716 & 0.71 & & & \\
\hline & SE5 & 3.69 & 0.777 & 0.77 & & & \\
\hline \multirow{4}{*}{$\begin{array}{l}\text { Application } \\
\text { Environment }\end{array}$} & AE1 & 3.66 & 0.711 & 0.88 & \multirow{4}{*}{0.892} & \multirow{4}{*}{0.626} & \multirow{4}{*}{0.863} \\
\hline & AE2 & 3.65 & 0.719 & 0.90 & & & \\
\hline & AE3 & 3.65 & 0.746 & 0.71 & & & \\
\hline & $\mathrm{AE} 4$ & 3.69 & 0.749 & 0.67 & & & \\
\hline \multirow{4}{*}{ Outcome Expectation } & OE1 & 4.29 & 0.635 & 0.74 & \multirow{4}{*}{0.888} & \multirow{4}{*}{0.668} & \multirow{4}{*}{0.884} \\
\hline & OE2 & 4.12 & 0.750 & 0.81 & & & \\
\hline & OE3 & 4.10 & 0.705 & 0.90 & & & \\
\hline & $\mathrm{OE} 4$ & 4.04 & 0.746 & 0.81 & & & \\
\hline \multirow{4}{*}{ Efficacy Expectation } & EE1 & 3.60 & 0.675 & 0.75 & \multirow{4}{*}{0.896} & \multirow{4}{*}{0.685} & \multirow{4}{*}{0.892} \\
\hline & EE2 & 3.80 & 0.646 & 0.90 & & & \\
\hline & EE3 & 3.82 & 0.673 & 0.87 & & & \\
\hline & EE4 & 3.69 & 0.704 & 0.78 & & & \\
\hline \multirow{4}{*}{$\begin{array}{l}\text { Teacher-centered ICT } \\
\text { Application Behavior }\end{array}$} & TC1 & 4.02 & 0.860 & 0.58 & \multirow{4}{*}{0.832} & \multirow{4}{*}{0.558} & \multirow{4}{*}{0.840} \\
\hline & TC2 & 3.74 & 0.886 & 0.85 & & & \\
\hline & TC3 & 3.51 & 0.895 & 0.72 & & & \\
\hline & TC4 & 3.72 & 0.916 & 0.81 & & & \\
\hline \multirow{5}{*}{$\begin{array}{l}\text { Student-centered ICT } \\
\text { Application Behavior }\end{array}$} & SC1 & 3.37 & 0.993 & 0.74 & \multirow{5}{*}{0.912} & \multirow{5}{*}{0.675} & \multirow{5}{*}{0.911} \\
\hline & SC2 & 3.38 & 1.006 & 0.88 & & & \\
\hline & SC3 & 3.34 & 1.022 & 0.83 & & & \\
\hline & SC4 & 3.10 & 1.022 & 0.81 & & & \\
\hline & SC5 & 3.37 & 0.994 & 0.84 & & & \\
\hline
\end{tabular}

Table 2. Construct discriminant validity.

\begin{tabular}{ccc}
\hline Fit Index & Recommended Level of Fit & Proposed Research Model \\
\hline CMIN/DF & $<3$ & 1.792 \\
GFI & $>0.9$ & 0.900 \\
RMR & $<0.05$ & 0.037 \\
RMSEA & $<0.05$ & 0.038 \\
NFI & $>0.9$ & 0.923 \\
CFI & $>0.9$ & 0.964 \\
\hline
\end{tabular}

An alternative model was calculated to obtain a better model (Figure 3). In Section 2, we inferred from other research conclusions $[24,30,31]$ that outcome expectation is irrelevant to student-centered ICT application behavior. However, these studies might have differences in the technology application development stage and cultural environment. In China, Education informatization has a top-down driving force; therefore, the outcome expectation might affect teacher attempts at teaching innovations and student-centered teaching behaviors. Thus, we added the assumed path "outcome expectation is a significantly positive correlation to student-centered ICT application behavior." The results showed the goodness-of-fit indicators of this model $\left(\chi^{2} / \mathrm{df}=2.77, \mathrm{CFI}=0.943, \mathrm{TLI}=0.936\right.$, RMSEA $=0.059$, SRMR $=0.055)$ fulfilled the basic requirements of the model fitting standards $\left(\chi^{2} / \mathrm{df}<3\right.$, CFI $>0.90$, TLI $>0.90$, RMSEA $<0.08$, and SRMR $\left.<0.08\right)$, which suggested the following: the fitting indicators of the adjusted model surpassed the original model; SRMR met the basic requirements; the refined hypothesis model is highly consistent with the variables reflected in the actual data and established the model. 


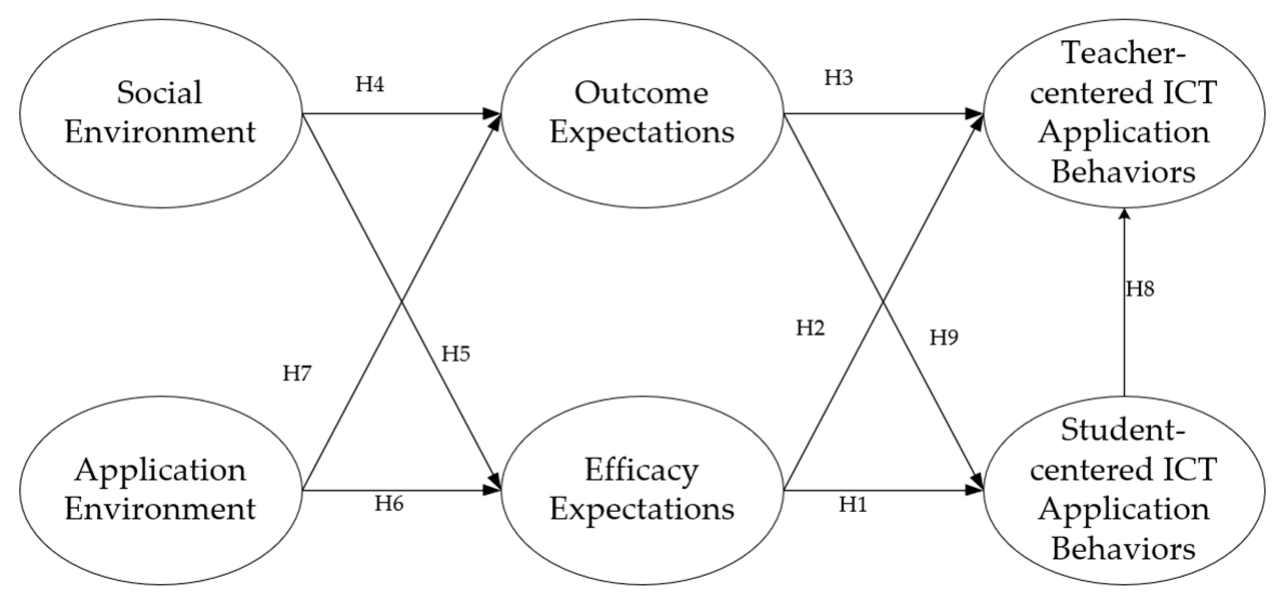

Figure 3. The refined model.

\subsection{Path Analysis}

Of note, $R^{2}$ represents the ratio of the interpretable variance to the total variance; the higher the value, the higher the interpretation ability. Chin [50] proposed that $R^{2}>0.67$ represents "high" interpretation ability, 0.33 represents "moderate" interpretation ability, and 0.19 represents "low" interpretation ability. As shown in Figure 4, this model explained $37.3 \%$ of the variance in teacher efficacy expectations, $37.4 \%$ of the variance in teacher outcome expectations, $40.8 \%$ of the variance in teacher-centered ICT application behaviors, and $70.8 \%$ of the variance in teacher-centered ICT application behaviors; this comprehensively established a moderate interpretation ability of this model.

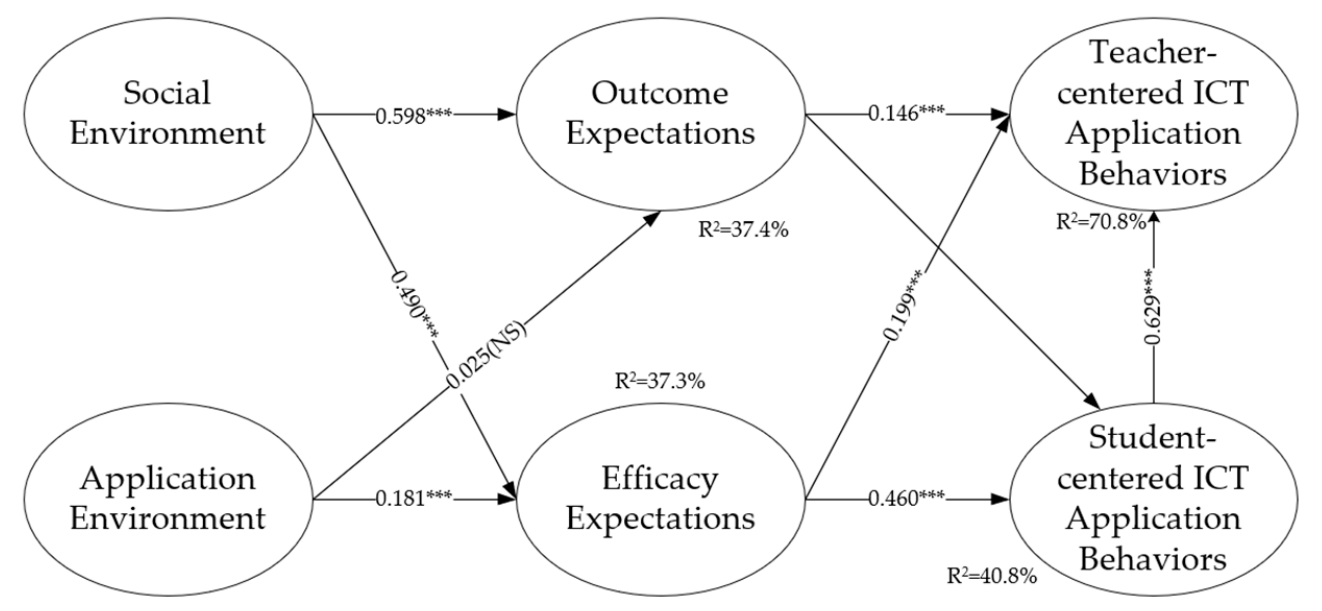

Figure 4. Results of the structural model. Note: ${ }^{* * *} p<0.001$; NS, not significant.

\subsubsection{Effect Analysis}

Except for one hypothesized relation (H7), all other hypotheses were empirically confirmed by the current dataset (Table 3). Overall, eight of the nine hypotheses in the improved model were supported. For the six assumptions associated with confirmation (H1, H2, H3, H4, H5, H6, and H8), as anticipated, one hypothesis (H7) did not match expectations. This study confirmed the modified relationship (H9). A specific analysis follows, and the magnitude of each path coefficient depicts the magnitude of relevant influence. 
Table 3. Test of hypotheses in the structural model.

\begin{tabular}{cccc}
\hline No. & $\begin{array}{c}\text { Hypothesized } \\
\text { Relation }\end{array}$ & $\begin{array}{c}\text { Standardized } \\
\text { Estimates }\end{array}$ & Test Results \\
\hline $\mathrm{H} 1$ & $\mathrm{EE} \rightarrow \mathrm{SC}$ & $0.460^{* * *}$ & Supported \\
$\mathrm{H} 2$ & $\mathrm{EE} \rightarrow \mathrm{TC}$ & $0.199^{* * *}$ & Supported \\
$\mathrm{H} 3$ & $\mathrm{OE} \rightarrow \mathrm{TC}$ & $0.146^{* * *}$ & Supported \\
$\mathrm{H} 4$ & $\mathrm{SE} \rightarrow \mathrm{OE}$ & $0.598^{* * *}$ & Supported \\
$\mathrm{H} 5$ & $\mathrm{SE} \rightarrow \mathrm{EE}$ & $0.490^{* * *}$ & Supported \\
$\mathrm{H} 6$ & $\mathrm{AE} \rightarrow \mathrm{EE}$ & $0.181^{* * *}$ & Supported \\
$\mathrm{H} 7$ & $\mathrm{AE} \rightarrow \mathrm{OE}$ & 0.025 & Unsupported \\
$\mathrm{H} 8$ & $\mathrm{SC} \rightarrow \mathrm{TC}$ & $0.629^{* * *}$ & Supported \\
$\mathrm{H} 9$ & $\mathrm{OE} \rightarrow \mathrm{SC}$ & $0.306^{* * *}$ & Supported \\
\hline Notes: $^{* * *} p<0.001$. & & &
\end{tabular}

- The social environment exerted a positive impact on both outcome expectation and efficacy expectation, aligning with the hypothesis proposed in the previous study; this suggested the social environment is crucial to teacher psychological perception of technology application in teaching. Meanwhile, the coefficients of the two paths (H4: $\beta=0.598>\mathrm{H} 5: \beta=0.490, p<0.001$ ) suggested the social environment exerted a greater impact on the outcome expectation than the efficacy expectation. Thus, for teachers, the social environment exerts a more positive impact on the benefits of information-based teaching than they perceive.

- The application environment exerted a positive impact on the outcome expectation (H6: $\beta=0.181, p<0.01$ ), and partially supported the research hypothesis; however, the application environment exerted no significant impact on the efficacy expectation (H7: $\beta=0.025, p>0.01)$. This conclusion corroborated the research hypothesis and suggested the technology application environment had no direct impact on teacher efficacy expectations.

- Outcome expectation exerted a positive impact on teacher-centered ICT application behavior (H3: $\beta=0.146, p<0.01)$, corroborating the study hypothesis. In addition, outcome expectation has a revised relationship with student-centered ICT application behavior (H9: $\beta=0.306, p<0.01)$ this confirmed the influence relationship between the two. Compared with the teacher-centered technology application behavior, outcome expectation exerted a stronger influence on student-centered ICT application behaviors.

- Efficacy expectation exerted a positive impact on teacher-centered ICT application behavior (H2: $\beta=0.199, p<0.01)$, and student-centered ICT application behavior (H1: $\beta=0.460, p<0.01)$. These results aligned with their respective hypotheses. The effect of efficacy expectation on student-centered ICT application behavior exceeded teachercentered ICT application behavior. Generally, compared with teacher-centered ICT application behavior, student-centered ICT application behavior was more influenced by both teacher expectations.

- Student-centered ICT application behavior exerted a positive impact on the teachercentered ICT application behavior (H8: $\beta=0.629, p<0.01)$. That result showed when teacher technology application becomes learner-centered, it promoted teachercentered ICT application behavior because student-centered ICT application behavior exerts a strong positive effect on the teacher-centered ICT application behavior.

The effect analyses revealed differences in the direct influencing factors of the two types of teacher ICT-integrated teaching behaviors. The student-centered ICT application behavior was more influenced by individual factors, and it also positively affected teachercentered ICT application behaviors.

\subsubsection{Mediated Effects}

To examine the mediated effects of outcome expectation, efficacy expectation, and student-centered ICT application behavior, indirect effects were validated using the boot- 
strapping analysis proposed by Preacher and Hayes [53]. The statistical significance of the mediating effects was determined based on a $95 \%$ confidence interval (CI), and the number of samples was set to 1000 [46]. Table 4 shows the results.

- The social environment indirectly affects student-centered ICT application behavior and teacher-centered ICT application behavior through outcome expectation or efficiency expectation. These results indicated that outcome expectation and efficacy expectation played crucial mediating roles between social environment and teacher ICT application behaviors. From the standpoint of effect coefficient, the indirect effect of the social environment on teacher-centered and student-centered ICT application behaviors were approximately the same; the standardized indirect effects were 0.408 and 0.442 , respectively. Comparing these two indirect influences with a direct one $(\mathrm{H} 1, \mathrm{H} 2, \mathrm{H} 3$, and H9), the indirect effect coefficient was larger, which indicated the indirect effect was more effective than direct effects regarding outcome expectation and efficacy expectation influences on teacher technology application behavior. Thus, changing environmental factors to influence teacher technology application behavior will bring better results.

- The application environment cannot directly or indirectly affect student-centered and teacher-centered ICT application behaviors, which implied that no significant mediating effect existed between outcome expectation and efficacy expectation on the two types of teacher ICT application behavior and application environment. However, both outcome and efficacy expectations directly impact teacher ICT application behavior.

- The outcome and efficacy expectations indirectly affect the teacher-centered ICT application behavior through the student-centered ICT application behavior. This implies that outcome expectation $\rightarrow$ student-centered ICT application behavior $\rightarrow$ teachercentered ICT application behavior $(\beta=0.192)$ and efficacy expectation $\rightarrow$ studentcentered ICT application behavior $\rightarrow$ teacher-centered ICT application behavior $(\beta=$ 0.289). Looking at the effective value between outcome and efficacy expectations on teacher-centered ICT application behavior, the indirect effect coefficient exceeded the direct effect coefficient, which implied that student-centered ICT application behavior had a crucial mediating effect. Thus, we need to encourage teachers to shift to learner-centered ICT applications, which can also improve the teacher-centered ICT application.

Table 4 . The boot-strapping analysis to examine the mediated effects.

\begin{tabular}{|c|c|c|c|c|c|c|c|c|}
\hline & \multicolumn{2}{|c|}{$\begin{array}{l}\text { Application } \\
\text { Environment }\end{array}$} & \multicolumn{2}{|c|}{ Social Environment } & \multicolumn{2}{|c|}{ Efficacy Expectation } & \multicolumn{2}{|c|}{ Outcome Expectation } \\
\hline & SIE & $p$ & SIE & $p$ & SIE & $p$ & SIE & $p$ \\
\hline $\begin{array}{l}\text { Student-centered ICT } \\
\text { Application Behavior }\end{array}$ & 0.091 & 0.11 & 0.408 & $0.001^{* * *}$ & $\cdots$ & $\cdots$ & $\cdots$ & $\cdots$ \\
\hline $\begin{array}{l}\text { Teacher-centered ICT } \\
\text { Application Behavior }\end{array}$ & 0.097 & 0.14 & 0.442 & $0.001^{* * *}$ & 0.289 & $0.000 * * *$ & 0.192 & $0.001 * * *$ \\
\hline
\end{tabular}

Note: ${ }^{* *} p<0.001$. SIE, standardized indirect effects. ... means that there is no mediating effect between two variables.

The mediation analysis revealed similar indirect influences of the two teacher ICTintegrated teaching behavior types, and a mutual influence relationship exists between the two. Similarly, both types of teacher ICT-integrated teaching behaviors were not indirectly affected by the application environment, but indirectly affected by the social environment. This indirect influence surpassed the direct influence of individual factors. The difference is that when the student-centered ICT application behavior was a moderator, individual outcome and efficacy expectations exerted a greater indirect impact on the teacher-centered ICT application behavior. In other words, more significant effects to promote teacher ICT-integrated teaching will occur by adjusting the environment and 
influence the teacher-centered ICT application behavior through development of studentcentered ICT application behavior.

\section{Discussion}

This study explored factors influencing different types of teacher ICT-integrated teaching behaviors to promote the development and reform of ICT-integrated teaching. Accordingly, our research, based on Bandura's social learning theory and relevant review, presented hypotheses and used SEM to test the following: relationships among teacher-centered ICT application behaviors; , student-centered ICT application behaviors and outcome expectation; , efficacy expectation;, application environment; , and social environment; this was followed by an analysis of the results.

This study found that, compared with teacher-centered teaching, outcome expectation, efficacy expectation, social environment, and application environment affected studentcentered teaching more. This implied that student-centered teaching requires a more potent internal driving force within teachers and consumes more internal expectations of teachers, as well as more information and energy support from the environment. Previous studies claimed that teacher efficacy and outcome expectations played a moderating role between the external environment and teacher ICT-integrated teaching behaviors [54]; the results of this study corroborate those studies. Moreover, this study further divided teacher ICT-integrated teaching behaviors into student-centered and teacher-centered, and found that teacher efficacy and outcome expectations exerted a stronger moderating effect on learner-centered teaching behaviors than on teacher-centered behaviors, while social environment also exerted a greater indirect influence. Moreover, this study further discovered the student-centered technology application, as a mediator, influenced the teacher-centered technology application more effectively than the efficacy expectation and outcome expectation directly. This finding aligns with the previous research suggesting that learner-centered instruction is a more complex form of instruction than teacher-centered instruction [55]. The application environment and social environment found in this study exerted stronger impacts on student-centered ICT application behavior, which suggested we should pay more attention to the overall construction of the application and to social environments when implementing learner-centered teaching reform.

This study further divided self-efficacy into two categories-outcome expectation and efficacy expectation. Overall, these results agreed with most previous findings that individual psychological factors, such as teacher self-perception and beliefs, correlated with student-centered teaching $[56,57]$. Furthermore, we found that in self-efficacy, efficacy expectation exerted a more significant impact on this teaching method than outcome expectation, which also agreed with previous studies. Internal motivation had a more significant impact on people's behavior than external motivation. Nevertheless, as found in previous studies, teaching methods such as mobile learning and virtual environment learning in the section of basic pedagogy did not influence teacher beliefs and other factors, and could be related to the nature of samples involved in this study. Of note, the samples in this study did not define the teaching methods, and their sample groups were highly targeted; this indicated that teacher beliefs and attitudes did not affect the student-centered teaching method, and may be due to the relationship between the specific teaching method and the maturity of that method.

In addition, we found that in social and application environments, the social environment exerted a greater impact on teacher self-efficacy. This suggested that teacher recognition of their technology application capabilities and judgments of the benefits due to the use of information technology was due in large part to the social environment; this included support from leaders, colleagues, experts, and job training institutions and agreed with previous reports $[32,58,59]$. In contrast, the application environment exerted no significant impact on the teacher outcome expectation but significantly affected the efficacy expectation and could be related to the development stage of Education informatization. The previous stage of China's Education informatization construction solved the 
application problems of school application environment construction and teacher basic application. Through this development stage, teachers have more general awareness of informatization teaching and have the basic ability to use technology. Thus, although the application environment still influences teacher feeling of their abilities, teachers realized that despite the general upgrade of the application environment, the key influencing factor of ICT-integrated teaching was no longer the application environment because it exerted no significant impact on teacher outcome expectations, nor a significant indirect impact on ICT application behavior. Hence, when further promoting ICT-integrated teaching, the focus should be on optimizing the social environment of teacher technology application.

This study supports shifting the application of information technology to learnercentered. Developing student-centered ICT application behavior not only facilitates teaching reform but also affects teacher-centered ICT application behavior. For the professional development of teachers, compared with the development of teacher-centered technology application skills, student-centered teaching can bring overall improvement. In addition, optimizing the social environment improves teacher sense of self-efficacy and helps teachers develop student-centered ICT application behavior to support their transition to learner-centered teaching reform. Such ICT-integrated teaching reform helps develop student lifelong learning abilities, Educational equity in the classroom, and enhances the teacher professional abilities of teacher. These serve as driving forces to support sustainable Education development. This conclusion not only specifically applies to teaching reforms under the background of Chinese Education informatization, but also refers to ICT-integrated teaching reforms and classroom teaching transformations at large. Nevertheless, our sample concentrated on primary and secondary school teachers and, therefore, has certain cultural limitations. In the future, our focus will examine this problem on an international scale.

\section{Conclusions}

To examine the influencing factors of different types of teacher ICT-integrated teaching behaviors and to assist teachers in transforming their methods to learner-centered teaching, this study adopted SEM to determine differences and correlations among teacher ICT teaching behaviors, individual factors, and environmental factors. The findings confirm that teacher-centered ICT application behavior positively correlates to student-centered ICT application behavior, and efficacy expectation positively correlates to student-centered ICT application behavior and teacher-centered ICT application behavior. In addition, the outcome expectation positively correlates to teacher-centered ICT application behavior as well as student-centered ICT application behavior; this differs from previous research results and may be due to the specific methods involved. Besides verifying the impact of social environment on efficacy expectation and outcome expectation, this study reports that, unlike previous studies, despite exerting a significant impact on efficacy expectation, application environment had no significant impact on outcome expectation and could be due to the development of ICT teaching equipment and functions.

This study suggested a division of teacher behavior into two categories, teachercentered ICT application behavior and student-centered ICT application behavior. This division helped us understand the conditions for teacher to transform their teaching methods, thereby helping us support the development of teachers into learner-centered Educators. That division also confirmed the significance of classifying information-based teaching behaviors and offered more detailed results than previous studies [14]. Meanwhile, the classification advanced research on influencing factors of ICT teaching, which is important as researchers continue to focus attention on adjusting influencing factors from an innovation diffusion perspective, TAM, and technological barriers, but lack the classification of ICT teaching behavior. This study also divided self-efficacy into two categories-outcome expectation and efficacy expectation-bringing more meaningful research results by elucidating the role of different psychological expectations in developing the digital teaching abilities of teachers. Verification and adjustment of the hypothesis 
model allowed us to understand the organizational network of the teaching environment, psychology, and behavior of ICT-integrated teaching behaviors. In addition, in the current stage of development, the application environment has a weakening influence on teacher digital teaching behavior; however, social environmental factors exert a crucial impact on teachers. Thus, we can improve the professional communication environment and leadership mechanism in schools, with professional training and expert guidance, to support teachers in developing digital teaching competence; we can also stimulate teacher output of student-centered ICT application behavior, increase the sense of self-efficacy of ICT teaching, and form a virtuous circle within a digital teacher professional development ecology. The transformation of student-centered ICT-integrated teaching will contribute to student lifelong learning and teacher professional development, thereby promoting the sustainable development of Education.

Supplementary Materials: The following are available online at https:/ / www.mdpi.com/article/1 $0.3390 /$ su132212614/s1.

Author Contributions: Conceptualization, Z.C.; Writing-Original Draft, J.Z.; Methodology, J.Z., J.M. and Z.L.; Writing-Review \& Editing, J.Z.; Formal analysis, J.M; Resources, Z.L.; Funding acquisition, Z.C. and Z.L. All authors have read and agreed to the published version of the manuscript.

Funding: The National Natural Science Foundation of China funded this research (Project No. 62077022, Project No. 62077017).

Institutional Review Board Statement: This study was approved by the Institutional Review Board of Central China Normal University, and written informed consent was provided by all participants.

Informed Consent Statement: Informed consent was obtained from all participants included in the study.

Data Availability Statement: Data available in a publicly accessible repository. The data presented in this study are openly available in [FigShare] at [https: / / figshare.com/articles/dataset/Research_on_t he_Influencing_Factors_of_Teachers_Information_and_Communications_Technology_integrated_Te aching_Behaviors_Oriented_toward_Learner-centered_Reform/14672406].

Conflicts of Interest: The authors declare no conflict of interest.

\section{References}

1. European Commission Education and Training. Council Conclusions on School Development and Excellent Teaching. 2017. Available online: https:/ / ec.europa.eu/Education/policies/school/teaching-professions_en (accessed on 3 May 2017).

2. Department for Education. The Standard for Teachers' Professional Development. 2016. Available online: https://assets.publi shing.service.gov.uk/government/uploads/system/uploads/attachmentdata/file/537030/160712_-_PD_standard.pdf (accessed on 24 February 2016).

3. Chinese Ministry of Education. Education Informatization 2.0 Action Plan. 2013. Available online: http://www.moe.gov.cn/srcsi te/A16/s3342/201804/t20180425_334188.html (accessed on 3 June 2013).

4. Rogers, E.M.; Simon, S. Diffusion of Innovations, 5th ed.; Free Press: New York, NY, USA, 2003.

5. Wang, S.; Yu, H.; Hu, X.; Li, J. Participant or spectator? Comprehending the willingness of faculty to use intelligent tutoring systems in the artificial intelligence era. Br. J. Educ. Technol. 2020, 51, 1657-1673. [CrossRef]

6. Huang, C.; Wang, H.; Yang, C.; Steven, J.H. A Derivation of Factors Influencing the Diffusion and Adoption of an Open Source Learning Platform. Sustainability 2020, 12, 7532. [CrossRef]

7. Sansom, D.W. Reinvention of classroom practice innovations. ELT J. 2017, 71, 423-432. [CrossRef]

8. Davis, F.D. A technology acceptance model for empirically testing new end-user information systems: Theory and results. Ph.D. Thesis, Massachusetts Institute of Technology, Cambridge, MA, USA, 1985.

9. Ranellucci, J.; Rosenberg, J.M.; Poitras, E.G. Exploring pre: Ervice teachers' use of technology: The technology acceptance model and expectancy-value theory. J. Comput. Assis. Learn. 2020, 36, 810-824. [CrossRef]

10. Koh, J.H.L.; Chai, C.S.; Lim, W.Y. Teacher professional development for TPACK-21CL: Effects on teacher ICT integration and student outcomes. J. Educ. Comput. Res. 2017, 55, 172-196. [CrossRef]

11. Brickner, D.L. The Effects of First and Second-Order Barriers to Change on the Degree and Nature of Computer Usage of Mathematics Teachers: A Case Study; Purdue University, ProQuest Dissertations Publishing: Ann Arbor, MI, USA, 1995 ; pp. 37-47.

12. Tsai, C.; Chai, C.S. The "third"-order barrier for technology-integration instruction: Implications for teacher Education. Aust. J. Edu. Technol. 2012, 28, 1057-1060. [CrossRef] 
13. Makki, T.W.; O’Nea, L.T.J.; Cotton., S.R. When first-order barriers are high: A comparison of second-and third-order barriers to classroom computing integration. Comput. Edu. 2018, 120, 90-97. [CrossRef]

14. Liu, H.; Wang, L.; Koehler, M.J. Exploring the intention-behavior gap in the technology acceptance model: A mixed-methods study in the context of foreign-language teaching in China. Br. J. Edu. Technol. 2019, 50, 2536-2556. [CrossRef]

15. Gordon, C.; Debus, R. Developing deep learning approaches and personal teaching efficacy within a preservice teacher Education context. Br. J. Edu. Psychol. 2011, 72, 483-511. [CrossRef]

16. Zhou, X.; Chen, L.H.; Chen, C.L. Collaborative learning by teaching: A pedagogy between learner-centered and learner-driven. Sustainability 2019, 11, 1174. [CrossRef]

17. Coronado, J.M.; Moyanom, A.; Romero, V.; Rodríguez, J. Student long-term perception of project-based learning in civil engineering Education: An 18-year ex-post assessment. Sustainability 2021, 13, 1949. [CrossRef]

18. The United Nations Educational, Scientific and Cultural Organization. Transforming Our World: The 2030 Agenda for Sustainable Development. Economic and Trade Section of the Permanent Mission to the United Nations at Geneva. 2016. Available online: http:/ / genevese.mofcom.gov.cn/article/wjysj/201604/20160401295679.shtml (accessed on 4 May 2016).

19. Department for Education, Ministry of Education of the People's Republic of China. Action Plan for the Revitalization of Education in the 21st Century. 1988. Available online: http:/ /www.moe.gov.cn/jyb_sjzl/moe_177/tnull_2487.html (accessed on 24 December 1988).

20. Department for Education, Ministry of Education of the People's Republic of China. Opinions of the Ministry of Education on the Implementation of the National Information Technology Application Ability Improvement Project 2.0 of Primary and Secondary School Teachers. 2019. Available online: http:/ / www.gov.cn/xinwen/2019-04/03/content_5379203.htm (accessed on 3 April 2019).

21. Erdem, M. The effects of the blended teaching practice process on prospective teachers' teaching self-efficacy and epistemological beliefs. Eurasian J. Educ. Res. 2008, 8, 81-98.

22. Joo, Y.J.; Park, S.; Lim, E. Factors influencing preservice teachers' intention to use technology: TPACK, teacher self-efficacy, and technology acceptance model. Edu. Technol. Soc. 2018, 21, 48-59.

23. Ertmer, P.A. Addressing first-and second-order barriers to change: Strategies for technology integration. Educ. Technol. Res. Dev. 1999, 47, 47-61. [CrossRef]

24. Bandura, A. Social Learning Theory, 3rd ed.; Prentice-Hall: Englewood Cliffs, NJ, USA, 1997; pp. 59-64.

25. Bandura, A. Self-Efficacy: The Exercise of Control, 3rd ed.; Freeman: New York, NY, USA, 1997; pp. 32-36.

26. Bandura, A.; Freeman, W.H.; Lightsey, R. Self-efficacy: The exercise of control. J. Cogn. Psychother. 1999, 13, 158-166. [CrossRef]

27. Lai, T.L.; Lin, H.F. An investigation of the relationship of beliefs, values and technological pedagogical content knowledge among teachers. Technol. Ped. Edu. 2018, 27, 445-458. [CrossRef]

28. Kim, C.; Kim, M.K.; Lee, C.; Spector, J.M.; Demeester, K. Teacher beliefs and technology integration. Teach. Teach. Edu. 2013, 29, 76-85. [CrossRef]

29. Vongkulluksn, V.W.; Xie, K.; Bowman, M.A. The role of value on teachers' internalization of external barriers and externalization of personal beliefs for classroom technology integration. Comput. Educ. 2018, 118, 70-81. [CrossRef]

30. Ertmer, P.A.; Ottenbreit-Leftwich, A.T.; Sadik, O.; Sendurur, E.; Sendurur, P. Teacher beliefs and technology integration practices: A critical relationship. Comput. Educ. 2012, 59, 423-435. [CrossRef]

31. Hatlevik, K.R.; Hatlevik, E. Examining the relationship between teachers' ICT self-efficacy for Educational purposes, collegial collaboration, lack of facilitation and the use of ICT in teaching practice. Front. Psychol. 2018, 9, 935. [CrossRef]

32. Mills, K.; Ketelhut, D.J.; Gong, X. Change of teacher beliefs, but not practices, following integration of immersive virtual environment in the classroom. J. Edu. Comput. Res. 2019, 57, 1786-1811. [CrossRef]

33. Ok, M.W.; Hughes, J.E.; Boklage, A. Teaching and learning biology with iPads for high school students with disabilities. J. Educ. Comput. Res. 2017, 56, 911-939. [CrossRef]

34. Mitchell, J.T.; Roy, G.; Fritch, S.; Wood, B. GIS professional development for teachers: Lessons learned from high-needs schools. Cartogr. Geogr. Inf. Sci. 2018, 45, 292-304. [CrossRef]

35. Khlaif, Z.N.; Kouraichi, B. How teachers in middle schools' design technology integration activities. Teach. Teach. Educ. 2018, 78, 141-150. [CrossRef]

36. Matthew, S.; Megan, H.; James, P.S. Educational infrastructure, professional learning, and changes in teachers' instructional practices and beliefs. Prof. Dev. Educ. 2019, 45, 599-613.

37. Ertmer, P.A.; Addison, P.; Lane, M.; Ross, E.; Woods, D. Examining teachers' beliefs about the role of technology in the elementary classroom. J. Res. Comput. Educ. 1999, 32, 54-72. [CrossRef]

38. Hew, K.F.; Brush, T. Integrating technology into K-12 teaching and learning: Current knowledge gaps and recommendations for future research. Educ. Technol. Res. Dev. 2007, 55, 223-252. [CrossRef]

39. Kopcha, T.J. Teachers' perceptions of the barriers to technology integration and practices with technology under situated professional development. Comput. Educ. 2012, 59, 1109-1121. [CrossRef]

40. Davis, F.D. Perceived usefulness, perceived ease of use, and user acceptance of information technology. MIS Quart. 1989, 13, 319-340. [CrossRef]

41. Ibili, E.; Resnyansky, D.; Billinghurst, M. Applying the technology acceptance model to understand math teachers' perceptions towards an augmented reality tutoring system. Educ. Inform. Tech. 2019, 24, 2653-2675. [CrossRef] 
42. Sánchez-Prieto, J.C.; Olmos-Miguelanez, S.; Garcia-Penalvo, F.J. Informal tools in formal contexts: Development of a model to assess the acceptance of mobile technologies among teachers. Comput. Hum. Behav. 2016, 55, 519-528. [CrossRef]

43. Walker, Z.; Kho, H.H.; Tan, D.; Lim, N. Practicum teachers' use of mobile technology as measured by the technology acceptance model. Asia. Pac. J. Educ. 2019, 9, 230-246. [CrossRef]

44. Hair, J.F.; Anderson, R.E.; Tatham, R.L.; Black, W.C. Multivariate Data Analysis, 5th ed.; Prentice-Hall: Englewood Cliffs, NJ, USA 1998; pp. 97-101.

45. Hu, L.T.; Bentler, P.M. Cutoff criteria for fit indexes in covariance structure analysis: Conventional criteria versus new alternatives. Struct. Equ. Model A Multidiscip. J. 1999, 6, 1-55. [CrossRef]

46. Cheung, G.W.; Lau, R.S. Testing mediation and suppression effects of latent variables: Bootstrapping with structural equation models. Organ. Res. Method 2008, 11, 296-325. [CrossRef]

47. Chin, W.W. The partial least squares approach to structural equation modeling. In Modern Method for Business Research; Marcoulides, G.A., Ed.; Psychology Press: New York, NY, USA, 1998; pp. 295-336.

48. Quintana, S.M.; Maxwell, S.E. Implications of recent developments in structural equation modeling for counseling psychology. Counsel. Psychol. 1999, 27, 485-527. [CrossRef]

49. Holland, D.D.; Piper, R.T. A technology integration Education (Tie) model: Millennial preservice teachers' motivations about technological, pedagogical, and content knowledge (Tpack) competencies. J. Educ. Comput. Res. 2014, 51, 257-294. [CrossRef]

50. Sang, G.; Tondeur, J.; Chai, C.S.; Dong, Y. Validation and profile of Chinese pre-service teachers' technological pedagogical content knowledge scale. Asia Pac. J. Teach. Educ. 2016, 44, 49-65. [CrossRef]

51. Tavakol, M.; Dennick, R. Making sense of Cronbach's alpha. Int. J. Med. Educ. 2011, 2, 53. [CrossRef]

52. Fornell, C.; Larcker, D.F. Evaluating structural equation models with unobservable variables and measurement error. J. Market. Res. 1981, 18, 39-50. [CrossRef]

53. Preacher, K.J.; Hayes, A.F. Asymptotic and resampling strategies for assessing and comparing indirect effects in multiple mediator models. Behav. Res. Method 2008, 40, 879-891. [CrossRef]

54. Soysal, Y.; Radmard, S. Barriers faced by teachers as an estimator of the effectiveness of reform-based initiatives. J. Educ. 2020, 0022057420943189. [CrossRef]

55. Keith, T.; Michael, P.; Paul, G. Phenomenographic pedagogy and a revised Approaches to teaching inventory. High. Educ. Res. Dev. 2005, 24, 349-360.

56. Ellis, D.M. The role of nurse Educators' self-perception and beliefs in the use of learner-centered teaching in the classroom. Nurse Educ. Pract. 2016, 16, 66-70. [CrossRef]

57. Maia, P.; Lu, S.; Jordan, H.; Annika, K.; Marilyne, S. Untangling a complex relationship: Teaching beliefs and instructional practices of assistant chemistry faculty at research-intensive institutions. Chem. Educ. Res. Pract. 2020, 21, 513-527.

58. Yada, A.; Tolvanen, A.; Malinen, O.P.; Imai-Matsumura, K.; Savolainen, H. Teachers' self-efficacy and the sources of efficacy: A cross-cultural investigation in Japan and Finland. Teach. Teach. Educ. 2019, 81, 13-24. [CrossRef]

59. Oddone, F. Cloud computing applications and services fostering teachers' self-efficacy. J. E Learn. Knowled. Soc. 2016, 12, 86-99. 